\title{
An Intervention to Remediate Unprofessional Behaviours of Pre-Clinical Medical Students
}

Submitted: 07-12-2020

Accepted: 10-04-2021

Online: 30-06-2021

\author{
Chan Choong Foong ${ }^{1}$, Nurul Atira Khairul Anhar Holder', \\ Aswini R Dutt ${ }^{2}$, Hidayah Mohd Fadzil ${ }^{3}$ \\ ${ }^{1}$ Medical Education and Research Development Unit, Faculty of \\ Medicine, Universiti Malaya, Kuala Lumpur, MALAYSIA \\ ${ }^{2}$ Department of Physiology, Yenepoya Medical College, \\ Yenepoya (Deemed to be University), Mangalore, INDIA \\ ${ }^{3}$ Department of Mathematics and Science Education, Faculty of \\ Education, Universiti Malaya, Kuala Lumpur, MALAYSIA
}

To cite this article: Foong CC, Khairul Anhar Holder NA, Dutt AR, Mohd Fadzil H. An intervention to remediate unprofessional behaviours of pre-clinical medical students. Education in Medicine Journal. 2021;13(2):83-90. https://doi.org/10.21315/eimj2021.13.2.7

To link to this article: https://doi.org/10.21315/eimj2021.13.2.7

\begin{abstract}
Remediating the unprofessional behaviours of medical students is essential because the unprofessional behaviours of medical practitioners could be traced back to their previous behaviours in medical schools. This study evaluated a programme that used reflection in remediating students with unprofessional behaviours. Personal and professional development (PPD) assignments have a "hidden curriculum" on professional behaviours expected of medical students. Seven students who repeatedly failed to complete the PPD assignments were required to attend a remediation programme. The remediation programme aims to help students reflect on their behaviours. They compared professional behaviours between medical practitioners and students and discussed unprofessional behaviours using actual cases. Thematic analysis was performed on the reflective essays of the students, collected at the beginning and the end of the remediation programme. At the beginning of the programme, students expressed anger because they felt that the PPD assignments were minor tasks. At the end of the programme, students expressed their regretful feelings; they recognised lessons learnt and developed corrective measures. A follow-up reported that the faculty no longer deemed the students unsatisfactory in their professional behaviours one year later. Reflection is recognised as useful in healthcare education, but there is a lack of published evidence to answer whether reflection can be learned. In this study, the students learnt to reflect on their previous professional behaviours, and they developed corrective measures to avoid the recurrence of these previous behaviours. The findings may imply that reflection could be taught and learned to cultivate professional behaviours among medical students.
\end{abstract}

Keywords: Professionalism, Reflection, Medical students, Remediation

Chan Choong Foong, Medical Education and Research Development Unit, Faculty of Medicine, Universiti Malaya, 50603 Kuala Lumpur, Malaysia

Email: foongchanchoong@um.edu.my 


\section{INTRODUCTION}

Medical students are expected to behave professionally with a strong moral sense (1-2). However, they may encounter situations in the hospitals that contravene such expectations (3). When students observe unprofessional behaviours in the clinical learning environment, they demonstrate either disturbance or habituation (3). Disturbance occurs when students experience distress due to increased exposure to ethical dilemmas (i.e., students are unable to justify the actions to achieve the learning outcomes). Habituation is described as a situation where students become compromised when they are exposed to unethical dilemmas (i.e., students can justify the actions to achieve the learning outcomes). Knowing these responses are essential as a clinical learning environment, both the formal (e.g., bedside teaching, lecture) and informal (e.g., role modelling, work environment) manners could influence students' behaviours as future doctors (3). For instance, habituation may lead students to comply with unprofessional behaviours and later demonstrate these behaviours. The need to intervene in unprofessional behaviours by students is further supported when the unprofessional conducts of medical practitioners could be traced back to their previous behaviours as medical students (4-6).

Societal expectations on behaviours of medical practitioners include their demonstration of "professional and ethical responsibilities, legal responsibilities, patient safety, and quality improvement, dealing with complexity and uncertainty, safeguarding vulnerable patients, and leadership and team working" (7). The American Board of Internal Medicine (ABIM) Foundation also emphasises the importance of commitment, honesty when dealing with patients, the confidentiality of patients, collaborative work, respect for one another and self-regulation (8). Despite these expectations, unprofessional behaviours still occur at the workplace. Some examples of unprofessional behaviours among medical practitioners include inaccurate or delayed medical reports, abusive to patients, refusal or failure to follow up patient management, inappropriate questions and comments posed to patients (9). Whereas a systematic review categorises unprofessional behaviours of medical students as (a) failure to engage (e.g., absenteeism, miss submission deadline); (b) dishonest behaviours (e.g., cheating, falsification of data); (c) disrespectful behaviours (e.g., poor communication, lack of sensitivities to the needs of others, arrogance); and (d) lack of self-awareness and self-improvement (e.g., defensive to constructive feedback and positive change) (10). In the Universiti Malaya, late submission or incomplete submission of assignments and poor communication with assessors are examples of unprofessional behaviours among students. It is worrying that a student who repeatedly informs "I forgot" or "I was not aware" (which may suggest lack of selfawareness and self-improvement) could be giving the same excuses when they become a medical practitioner. Professional behaviours of medical practitioners include exercising accountability for themselves and reflecting upon their actions. However, cognitive and skill competence might have been biasedly weighted more than the professionalism in medical training and practices (11). Cultivating professional behaviours among medical students is therefore essential.

While medical schools may have attempted to intervene in unprofessional behaviours among their students using assignments, role models, mentoring, coaching, counselling, or community service, currently, there is a marked lack of studies reporting the effectiveness of those remediation programmes (12-13). Reflection is also a potential intervention. By engaging in reflection, people learn to examine their previous experiences and behaviours, and they would come to a 
reasoned action when they face similar situations in the future (14). However, reports of using reflection as an intervention are rare in ASEAN medical schools (15). This study aims to evaluate a remediation programme aiming at intervening in the conduct of a few selected students. The remediation programme did not seek to punish the students. Instead, it was aimed at preventing subsequent unprofessional behaviours from happening again, as asserted by Papadakis et al. (5). Results of this study would contribute empirical evidence to support the development of guidelines for these remediation programmes (16).

\section{METHODS}

Personal and professional development (PPD) assignments in the medical programme at the authors' institution have a "hidden curriculum" on professional behaviours as students. In addition to the acquisition of knowledge and skills, the institution expects students to be accountable for timely submission of assignments, adherence to guidelines, complete submission and communication with assessors (whenever they encountered difficulties). A student, who is unable to complete an assignment will be given faceto-face advice and a written warning.

This study was conducted in a public university in Malaysia. There were 130 Year-1 and 120 Year-2 medical students in an anonymous academic session. Amongst these students, there were four Year-1 and three Year-2 medical students who demonstrated unprofessional behaviours. The students had repeatedly (i.e., three times and more) gave reasons such as "I forgot", "I was not aware of the assignments", "I only missed a part of the assignment", and "I was troubled by other matters" whenever they failed to complete the PPD assignments. At the end of their yearly academic session, the faculty deemed these students unsatisfactory in their professional behaviours as medical students. Consequently, these students were required to participate in a remediation programme.

This remediation programme aimed to help the students reflect on themselves. With guidance, they compared professional behaviours between medical practitioners and students and discussed unprofessional behaviours using real cases. Teaching methods included mini-lectures, interactive discussions (on relevant articles, videos and newspapers) with peers and remediation coaches, student presentations and fieldworks (i.e., interviews about the students' sense of professionalism when interacting with their patients, healthcare professionals and academic staff).

This study employed an interpretive qualitative research design to investigate how participants of the study interpreted their experiences in relation to unprofessional behaviours (17). Investigations into the students' beliefs, opinions and attitudes could be conducted using qualitative research methods to obtain an in-depth understanding of the participants (18).

The data collected were reflective essays of students submitted at the beginning and the end of the remediation programme. The students were guided in the reflective essays and an example is, "What have you reflected so far after you have attended all of the remediation sessions and the fieldwork?" Data analysis was performed on the data using QDA Miner Lite 2.0. Thematic analysis was conducted in six steps: familiarising with data, generating codes, searching for themes, reviewing the themes, defining the themes and write up (19). The thematic analysis process was iterative (move forward and back).

Reflexivity in qualitative research requests that the researchers re-evaluate their biases and initial assumptions, their relationship with the participants and their influences on the participants' behaviours (20). The first 
and second authors were the remediation coaches and analysts. They reminded each other to be as neutral as possible when analysing the data. They should be ready to accept findings that fall outside their initial assumption (20). The third and fourth authors cross-checked the findings and quotes to prevent cherry-picking of evidence.

\section{RESULTS}

Reflective essays of four Year-1 (three males and one female) and three Year-2 (three males) students were analysed. Four themes were produced, which described the thoughts of students in chronological order, from the beginning until the end of the remediation programme: (a) What did I feel?; (b) What do I feel now?; (c) What did I learn?; and (d) What would I do? Pseudonyms were used in the findings to prevent identifiable data.

\section{What Did I Feel?}

At the beginning of the remediation programme, the students were asked to recall their feelings when they were informed of the remediation process. The terms "angry/anger" and "frustration/ frustrating" appeared in six reflective essays out of the seven students. The students claimed, "Missing the three evaluations (the assignments) was not a big deal and the punishment was too much" and "it was a minor mistake". It seemed that the PPD assignments were not a part of his studies when Francis said, "I was frantically catching up on my studies, and I could not help but forgetting other tasks". Simon commented, "I didn't see it as important to warrant my full attention. Thus, I didn't read the instructions carefully, and I didn't care about this evaluation". For students, the PPD assignments seemed to be minor tasks compared to their acquisition of knowledge and skills.

\section{What Do I Feel Now?}

At the end of remediation, the students seemed to be aware and became regretful of their previous unprofessional behaviours. Winnie confessed, "I regret missing it (the assignment) and (should) not always use forgetfulness as an excuse for not completing my work". Francis also seemed to regret his actions, "I do feel regret and disappointed for what had happened previously as being unprofessional (diminished) our reputation as a medical doctor and undermine (patients') sense of trust towards doctors".

\section{What Did I Learn?}

Chris learnt that "I have come to realise that if I couldn't even do a small and simple task like the PPD (assignments) properly, how am I going to carry heavier responsibilities and duties in the future as a doctor. Another thing is, if I (did not) get rid of these ignorant and forgetful bad habits, I may put my patients' lives in danger in the future. This time, I only need to attend the remediation classes for my own mistakes, but in the future, I might pay a bigger price for the same kind of mistakes".

While being angry at the beginning of the programme, later Simon realised that "getting angry and frustrated cannot solve any problems. Only (by) remaining calm and treating the problem professionally can help (to) solve problems".

Winnie commented, "I have learned the importance of reflection in our daily life. We have to reflect to know our advantages and disadvantages. With the knowledge, we can improve our weaknesses and enhance our advantages to be a better person. Besides, I have learned (the meaning of) professionalism (as both) a medical student and doctor, and how to (become one)". Furthermore, Owen seemed to recognise that his reflection acted as a hidden curriculum in a medical programme when he wrote, "Not only that self-reflection is 
promoted among students and lecturers, but it also serves as a hidden curriculum".

\section{What Would I Do?}

At the end of the remediation programme, students developed their corrective measures. Winnie assured herself that "I promise not to repeat the same mistakes in the future and will make this my priority". Simon gave rationales that "I should take things more seriously and study the best I can to be true healthcare professional. There is nothing worse than being directly or indirectly responsible for patient's suffering due to your negligence or laziness".

Leonard also realised that "Now, the meaning of professionalism is crystal clear to me. I will make sure I apply what I have learnt from these few sessions in my future career". Alex planned to continue using reflection in his daily life, "I started to use these reflection models to reflect on myself on what I had done for the day and things that I should improve for the next day. Having a self-reflection once a day (is) good for ourselves as it always pushes us to do better and (help) to control negative emotions (from) influencing us".

The authors continued to monitor the completion of the PPD assignments of all students in the subsequent academic session. None of the students was again deemed by the faculty to be unsatisfactory in their professional behaviours.

\section{DISCUSSION}

Four themes were established from the thematic analysis, namely, (a) What did I feel?; (b) What do I feel now?; (c) What did I learn?; and (d) What would I do? These themes echo the generic process of reflection such as what happened? (e.g., I repeated missed assignments and had to attend remediation programme), why does it matter? (e.g., I felt angry, but I am regretful now), and what to do in the future? (e.g., I learnt the lessons, and I promise not to repeat the same mistakes in the future) (21). This generic process of reflection is also found in different reflection models such as Gibbs, Dewey, Mezirow, and Schon $(22-23)$.

Reflection is recognised to be useful in healthcare education $(21,24)$, but there is lacking published evidence to answer the question "can reflection be learned" (25). The findings suggested that the students were learning to reflect on their previous behaviours, and they developed corrective measures at the end of the remediation programme. In other words, it was a "yes" in response to the question "Can reflection be learned?"

Firstly, feelings trigger reflection. Feelings control the way people interpret facts and this interpretation is a part of the knowledge structure (26). In this study, the students expressed that they felt regret. Their strong feelings led to awareness and the awareness prompted one's more profound reflections on his/her behaviours (27). Secondly, in this study, the students noticed and judged what did not go well for their previous behaviours. Examples included recognising unprofessional behaviours could lead to disastrous consequences and negative emotions (i.e., anger and frustration) do not help to solve problems they faced. Students seemed to have stepped back from the events they experienced, and they reframed their previous experiences with new understanding (i.e., what constitutes professional behaviours) (26). Lastly, as the aim of reflection is to inform future actions, it is important to ensure corrective measures are planned (27-28). In this study, students promised that they would not repeat the same mistakes and use reflection to continue personal developments. As feelings, lessons learnt and the corrective measures taken are essential elements in reflection $(27,29)$, the findings suggested that the students learnt and reflected on their behaviours.

The findings of this study had several implications for future practice and research. First, the literature is uncertain whether 
the observable measures could predict the needs for remediation (16). This study examined the reasons given by students, such as "forgot", "was not aware of the assignments", "only missed a part of the assignment", and "was troubled by other matters" are possible observable measures. During the remediation programme, the students started to recognise that these reasons were regarded as unprofessional. It is a misconception that unprofessional behaviours are those such as cheating in the examination or falsifying data. Instead, they include the lack of insight into one own's behaviours $(10,16)$.

Second, in contrast to Chou's et al. (16) recommendation that remediation coaches should not become the remediation assessor, this study argues that the remediation coaches can observe reliable behaviours through sufficient personal engagement with the students. While taking students through the remediation process, they could recognise what had changed and what had not. Independent assessors might have no conflict of interest, but observer effects are possible. Last, this study encouraged the students to use reflective essays. However, to sustain their reflective practice after the remediation ends, a portfolio may be considered as a means to record their professional development (30). Self-reports are a common documentation tool for reflective practices (31), but follow-up interviews with the students may be useful in verifying the actual use of reflection in their daily practices (16).

\section{LIMITATIONS OF THE STUDY}

The study had a few limitations. First, the findings of the study may not be generalisable to other medical schools due to its qualitative nature and the small number of participants. As such, future studies should consider a larger cohort of participants. Second, to escape from the unsatisfactory grades, the participants might have manipulated their reflective essays to satisfy the assessors. The students can agree to disagree throughout the remediation programme to encourage open and honest conversation between the remediation coaches and students. Such an approach may help to enhance the trustworthiness of their reflective essays. Nevertheless, as the students had to submit the essays as part of the requirements, the long-term effects of the remediation should be studied (16). Last, as this is a mandatory remediation programme, the student participation is non-voluntary. However, non-identifiable data (e.g., pseudonyms, anonymity on ethnicity, age, and academic session) were adopted to reduce vulnerability.

\section{CONCLUSION}

It is crucial to remediate unprofessional behaviours at the early stages of a medical student profession, as it could have a deleterious effect on the further development of professionalism in medical training and practices. In this study, reflection is found to be useful in helping medical students to cultivate professional behaviours. Nonetheless, the learning processes need to be guided in the case of unconsciously incompetent beginners.

\section{ACKNOWLEDGEMENTS}

This study was supported by University of Malaya Research Fund Assistance (BKP) BK023-2016.

\section{REFERENCES}

1. General Medical Council. Medical students: professional values and fitness to practise. London: General Medical Council; 2009.

2. Yadav H, Jegasothy R, Ramakrishnappa S, Mohanraj J, Senan P. Unethical behavior and professionalism among medical students in a private medical university in Malaysia. BMC Med Educ. 2019;19(1):1-5. https://doi.org/10.1186/s12909-019-1662-3 
3. Monrouxe LV, Rees CE. "It's just a clash of cultures": emotional talk within medical students' narratives of professionalism dilemmas. Adv Health Sci Educ Theory Pract. 2012;17(5):671-701. https://doi.org/ 10.1007/s10459-011-9342-z

4. Ainsworth MA, Szauter KM. Student response to reports of unprofessional behavior: assessing risk of subsequent professional problems in medical school. Med Educ Online. 2018;23(1):1485432. https://doi.org/10.1080/10872981.2018.148 5432

5. Papadakis MA, Teherani A, Banach MA, Knettler TR, Rattner SL, Stern DT, et al. Disciplinary action by medical boards and prior behavior in medical school. New Engl J Med. 2005;353(25):2673-82. https://doi. org/10.1056/NEJMsa052596

6. Teherani A, Hodgson CS, Banach M, Papadakis MA. Domains of unprofessional behavior during medical school associated with future disciplinary action by a state medical board. Acad Med. 2005;80(10):S17-20. https://doi.org/10 $.1097 / 00001888-200510001-00008$

7. General Medical Council. Outcomes for graduates 2018. London: General Medical Council; 2020.

8. American Board of Internal Medicine (ABIM) Foundation. Medical professionalism in the new millennium: a physician charter. Ann Intern Med. 2002;136(3):243-6. https://doi.org/10.7326/ 0003-4819-136-3-200202050-00012

9. Rogers W, Ballantyne A. Towards a practical definition of professional behaviour. Journal of Medical Ethics. 2010;36(4):250-4. https://doi.org/10.1136/jme.2009.035121

10. Mak-van der Vossen M, van Mook W, van der Burgt S, Kors J, Ket JCF, Croiset $G$, et al. Descriptors for unprofessional behaviours of medical students: a systematic review and categorisation. BMC Med Educ. 2017;17:164. https://doi.org/10.1186/s12909 $-017-0997-\mathrm{x}$
11. Smith AF, Greaves JD. Beyond competence: defining and promoting excellence in anaesthesia. Anaesthesia. 2010;65(2):18491. https://doi.org/10.1111/j.1365-2044 $.2009 .06162 . x$

12. Hauer KE, Ciccone A, Henzel TR, Katsufrakis P, Miller SH, Norcross WA, et al. Remediation of the deficiencies of physicians across the continuum from medical school to practice: a thematic review of the literature. Acad Med. 2009;84(12):1822-32. https://doi.org/10 $.1097 /$ ACM.0b013e3181bf3170

13. Mak-van der Vossen $M$, Teherani A, van Mook W, Croiset G, Kusurkar RA. How to identify, address and report students' unprofessional behaviour in medical school. Med Teach. 2020;42(4):372-9. https://doi. org/10.1080/0142159X.2019.1692130

14. Clarke D, Graham M. Reflective practice: the use of reflective diaries by experienced registered nurses. Nursing Review. 1996;15(1):26-9.

15. Findyartini A, Sudarsono NC. Remediating lapses in professionalism among undergraduate pre-clinical medical students in an Asian institution: a multimodal approach. BMC Med Educ. 2018;18(1):88. https://doi.org/10.1186/s12909-018-1206-2

16. Chou CL, Kalet A, Costa MJ, Cleland J, Winston K. Guidelines: the dos, don'ts and don't knows of remediation in medical education. Perspect Med Educ. 2019;8(6):322-38. https://doi.org/10.1007/ s40037-019-00544-5

17. Merriam SB, Tisdell EJ. Qualitative research: a guide to design and implementation. San Francisco, California: Jossey-Bass; 2016.

18. Creswell JW, Poth CN. Qualitative inquiry and research design: choosing among five approaches. Los Angeles: SAGE Publications; 2018. 
19. Braun V, Clarke V. Using thematic analysis in psychology. Qual Res Psychol. 2006;3(2):77-101. https://doi.org/10.1191/ 1478088706qp063oa

20. Jootun D, McGhee G, Marland GR. Reflexivity: promoting rigour in qualitative research. Nurs Stand. 2009;23(23):42-7. https://doi.org/10.7748/ns.23.23.42.s50

21. Koshy K, Limb C, Gundogan B, Whitehurst $\mathrm{K}$, Jafree DJ. Reflective practice in health care and how to reflect effectively. Int J Surg Oncol. 2017;2(6):e20. https://doi.org/ 10.1097/IJ9.0000000000000020

22. Ménard L, Ratnapalan S. Reflection in medicine: models and application. Can Fam Physician. 2013;59(1):105-7.

23. Holder NAKA, Sim ZL, Foong CC, Pallath V. Developing a reflection guiding tool for underperforming medical students: an action research project. Tuning J High Educ. 2019;7(1):115-63. https://doi.org/10.18543/ tjhe-7(1)-2019pp115-163

24. Cole M. Reflection in healthcare practice: why is it useful and how might it be done? Work Based Learning in Primary Care. 2005;3:13-22.

25. Fragkos KC. Reflective practice in healthcare education: an umbrella review. Education Sciences. 2016;6:16. https://doi. org/10.3390/educsci6030027
26. Moon JA. A handbook of reflective and experiential learning: theory and practice. London: Routledge Falmer; 2004.

27. Sandars J. The use of reflection in medical education: AMEE Guide No. 44. Med Teach. 2009;31(8):685-95. https://doi.org/ $10.1080 / 01421590903050374$

28. Foong CC, Hassan H, Lee SS, Vadivelu J. Using students' formative feedback to advocate reflective teaching. Med Educ. 2015;49(5):535. https://doi.org/10.1111/ medu. 12697

29. Jayatilleke N, Mackie A. Reflection as part of continuous professional development for public health professionals: a literature review. J Public Health. 2013;35(2):308-12. https://doi.org/10.1093/pubmed/fds083

30. Mansvelder-Longayroux DD, Beijaard D, Verloop N. The portfolio as a tool for stimulating reflection by student teachers. Teach Teach Educ. 2007;23(1):47-62. https://doi.org/10.1016/j.tate.2006.04.033

31. Chaffey LJ, de Leeuw EJJ, Finnigan GA. Facilitating students' reflective practice in a medical course: Lliterature review. Educ Health. 2012;25(3):198. https://doi.org/10 .4103/1357-6283.109787 